\title{
Performance evaluation of rapid test potassium hydroxide for the diagnosis of onychomycosis.
}

1. MBBS, BSc, M.Phil (Microbiology),

Ph.D Scholar

Associate Professor Pathology

Quaid-e-Azam Medical College,

Bahawalpur, Pakistan.

2. MBBS, DCH, MCPS, FCPS

Associate Professor Pediatric

Medicine

Bahawal Victoria Hospital,

Bahawalpur.

3. MBBS, M.Phil (Biochemistry)

Assistant Professor Biochemistry

Quaid-e-Azam Medical College,

Bahawalpur.

Correspondence Address:

Dr. Muhammad Wajid Khurshid Sipra

Department of Pathology

Quaid-e-Azam Medical College,

Bahawalpur, Pakistan.

wajidkhurshid@gmail.com

Article received on:

14/11/2020

Accepted for publication:

30/04/2021

Muhammad Wajid Khurshid Sipra', Khawar Saeed Jillian², Tayyaba Batool ${ }^{3}$

ABSTRACT... Objective: To determine the potassium hydroxide $(\mathrm{KOH})$ sensitivity for the diagnosis of fungal nail infections. Study Design: Descriptive Case study. Setting: Department of Quaid-e-Azam Medical College Bahawalpur. Period: July 2017 to June 2020. Material \& Method: The nail specimen immersed in $20 \%$ Potassium hydroxide in Petri dish and incubated aerobically at 37Ć for 1 hours. Upon microscopy, the presence of hyphae or spores that considered the test was positive. Result: Out of three hundred forty clinical screened cases, the sensitivity of $\mathrm{KOH}$ mount was $55.29 \%$ true positive. Conclusion: $\mathrm{KOH}$ mount microscopy is simple and cost-effective techniques to diagnose superficial fungal infections in the primary care and Outpatient settings.

Key words: $\quad$ Fungal Elements, $\mathrm{KOH}$ Mount and Outpatient Department (OPD), Potassium Hydroxide $(\mathrm{KOH})$.

Article Citation: Sipra MWK, Jillian KS, Batool T. Performance evaluation of rapid test potassium hydroxide for the diagnosis of onychomycosis. Professional Med J 2021; 28(12):1793-1796. https://doi.org/10.29309/TPMJ/2021.28.12.6215

\section{INTRODUCTION}

Potassium hydroxide is a routinely performed diagnostic test for the superficial fungal infections. Fungal culture is the gold standard for diagnosing dermatophytosis but it since last two decades' available molecular techniques have improved the diagnostic procedure. ${ }^{1}$

Onychomycosis is a chronic fungal infection of the nails that affects $5.5 \%$ of the world population and represents $20 \%$ to $40 \%$ of all nail infections. Approximately $30 \%$ of cutaneous mycotic infections are due to onychomycosis. ${ }^{2}$

Globally the burden of onychomycosis raised. Trichophyton species and yeast or molds are the dominant isolating fungal agents. ${ }^{3}$ The mycological diagnosis performed by direct microscopy $\mathrm{KOH}$ is most cost effective techniques to identify the fungal elements but it does not allow the species identification. ${ }^{4}$

Fungal infection may be recognized initially yellow discoloration of the nail plate which is crumbly thickened rough debris. This dystrophic and thickened portion of nail causing pressure erosions of the nail bed. ${ }^{5}$

Onychomycosis is Greek word that derived from the "onyx" a nail and "mykes" a fungus ${ }^{6}$ which can be classified as, i) distolateral subungal; ii) superficial white; iii) proximal subungal; iv) candida v) total dystrophic onychomycosis. ${ }^{7}$ The trauma to nails are mostly occurring disease factor and peripheral vascular diseases, poor hygiene and chronic exposure of water is also significantly affects the nail beds. ${ }^{8}$ The nail fungal infection is much more observed in diabetes mellitus and HIV patients which was determined up to $40 \%$ in general population. The dermatophyte reporting increasingly in zones of temperate while moulds such as aspergillus species are commonly detection in tropical and subtropical countries. ${ }^{9,10,11}$

$\mathrm{KOH} 20 \%$ mount microscopy is simple, rapid and inexpensive laboratory techniques. However, experience is required to interpret the mount. ${ }^{12}$ 


\section{MATERIAL \& METHODS}

The clinically diagnosed $(n=340)$ cases of Onychomycosis enrolled to dermatology outpatient department, Bahawal Victoria Hospital Bahawalpur, Jinnah Postgraduate Medical Center Karachi and various dermatologist clinics. The duration of study was $1^{\text {st }}$ July 2017 to $30^{\text {th }}$ June 2020. Typically, Onychomycosis begins as a yellowish discoloration under the nail. The nail may thicken, become rough and crumbly and separate from the nail bed, and debris may accumulate under the nail. Thickening and dystrophy of the nail result in pressure erosions of the nail bed and Hyponychim. ${ }^{5} \mathrm{~A}$ detailed proforma filled after consent that containing the nail trauma, personal hygiene and other relevant history were noted. The specimen was selected the most affected nail. ${ }^{13}$ Cases were selected irrespective of age and gender. The exclusion criteria were already receiving antifungal and other systemic diseases. ${ }^{14}$

The affected nail was immersed in $20 \% \mathrm{KOH}$ and incubated at 37Ć for 1 hours. On microscopy of softened nail, the presence of fungal components like beaded spherical structure (spores), budding cells and thread like structure (hyphae) were observed and were considered for positive test. $^{15,16}$

\section{RESULTS}

Out of $(n=340)$ clinical diagnosed cases, the distribution of males was 220 while females were 120 . The $50 \%$ positivity of onychomycosis observed in age group of 21 to 30 -years. (Figure-1). $\mathrm{KOH}$ mount microscopy revealed true positive results in $55.29 \%$ cases while $44.71 \%$ cases were negative. (Table-l). This study showed $\mathrm{KOH}$ mount microscopy is a screening tool for fungal infection and is cost effective in population for establishing the disease in outpatient department and clinics.

\begin{tabular}{|c|c|c|}
\hline \multicolumn{1}{|c|}{ Test } & Positive n (\%) & Negative n (\%) \\
\hline $\mathrm{KOH}$ & $188(55.29 \%)$ & $152(44.71 \%)$ \\
\hline
\end{tabular}

Table-I. Descriptive analysis of diagnostic methods. $(\mathrm{N}=340)$.

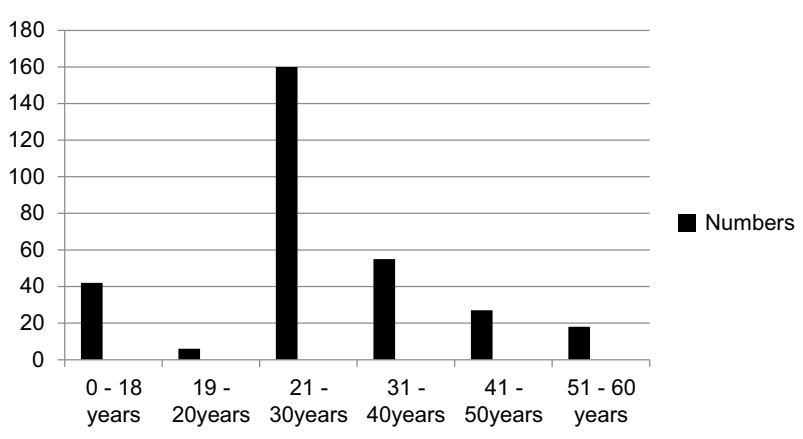

Figure-1. Distribution of age 1 group.

\section{DISCUSSION}

The $50 \%$ of nail diseases are caused by fungal infections. Several dermatophytes, nondermatophytes, moulds, and yeasts may be involved for these disorders, collectively known as onychomycosis. We aimed $\mathrm{KOH}$ mount microscopy, for the screening and establishing onychomycosis at outpatient departmrnt. ${ }^{17}$

Sensitivity of $\mathrm{KOH}$ mount observed by Ahmad R et $\mathrm{al}^{18}$ and Gianni $\mathrm{C}$ et $\mathrm{al}^{19}$ was $59 \%$ and $59.3 \%$ respectively is comparable with our results that is $55.29 \%$. Clinical cases of Onychomycosis by $\mathrm{KOH}$ microscopy by authors Wilsmann-Theis D et $\mathrm{al}^{20}$ concluded $48 \%$ positive cases and Subathra, $\mathrm{N}^{21}$ recovered $51 \%$ positive cases that are at par with our study. An observation by Jung MY et $\mathrm{al}^{22}$ showed $\mathrm{KOH}$ sensitivity was $55.9 \%$ consistent with our study results. The present study observed $\mathrm{KOH}$ positivity was $55.29 \%$ which is closely matched with Dass $\mathrm{S} \mathrm{M}$ et $\mathrm{al}^{23}$ who recovered $56 \%$ positive tests. The positivity of $\mathrm{KOH}$ mount microscopy of our study results compared with Konda $\mathrm{C}$ et al ${ }^{24}$ showed $4 \%$ lower ratio. Various other studies ${ }^{25,26}$ observed range of 4 to $12 \%$ higher than with our results comparison.

Fungal culture and other diagnostic tools are expensive, time consuming. The special expertise personals required for these tools and even they did not available in every pathology laboratory and not included for diagnostic criteria.

\section{CONCLUSION}

$\mathrm{KOH}$ mount microscopy is efficient, simple and cost-effective techniques to diagnose superficial fungal infections in the primary care and 
Outpatient settings.

\section{RECOMMENDATION}

$\mathrm{KOH}$ mount microscopy arrangements at OPD and primary care settings helpful for the detection of fungal elements and treat accordingly.

\section{Copyright@ 30 Apr, 2021.}

\section{REFERRENCES}

1. Karaman B F, Topal S G, Aksungur V L et al; Successive potassium hydroxide testing for improved diagnosis of tinea pedis. bcutis. 2017; 100: 110-114.

2. Adekhand $\mathrm{S}, \mathrm{Pal} \mathrm{S}$, Sharma $\mathrm{N}$ et al; Incidence and epidemiology of onychomycosis in patients visiting a Tertiary Care Hospital in India. Cutis. 2015; 95:E20-E25.

3. Ahmed R, Kharal S.A, Durrani M.A et al; Comparison of $\mathrm{KOH}$ Mount \& Fungal culture in the diagnosis of onychomycosis. PJMH S VOL, 6 No, 1 Jan-Mar 2012, 143.

4. Bonifaz A, Rios-Yuil J.M, Arenas R, et al; Comparison of direct microscopy, culture and calcofluor white for the diagnosis of onychomycosis. Rev Iberoam Micol. 2013; 30(2):109-111.

5. Rich $P$. Onychomycosis and tinea pedis in patient with diabetes. J Am Acad Dermatol 2000; 3:130-134.

6. Kaur R, Kashyap B, and Bhalla P. Onychomycosisepidemiology, diagnosis and management. Indian Journal of Medical Microbiology (2008); 26(2):108-16.

7. Lone R, Showkat H. I, Bashir D et al; Clinico-Mycological pattern of onychomycosis: A single center one-year study in Kashmir-North India. Eur J Gen Med 2013; 10(3): 150-153.

8. Ahmed R, Kharal SA, Durrani MA et al; Frequency of Candida in onychomycosis. J Pak Med Assoc. Vol. 63, No.3, March 2013, 350-353.

9. Westerberg DP, Voyack MJ. Onychomycosis: Current trends in diagnosis and treatment. American family physician. 2013 Dec 1; 88(11):762-70.

10. Ellabib M.S, Agaj M, Khalifa Z, Kavanagh K. Yeasts of the genus Candida are the dominant cause of onychomycosis in Libyan women but not men: Results of a 2-year surveillance study. British Journal of Dermatology 2002; 146: 1038-1041.

11. Zisova L, Chokoeva A, et al; Onychomycosis and childrena multicenter study. Acta Medica Bulgarica, Vol. XLII, 2015, № 1.
12. Kurade SM, Amladi SA, Miskeen AK. Skin scraping and a potassium hydroxide mount. Indian J Dermatol Venereol Leprol 2006; 72:238-241.

13. Satpathi $P$, Achar A, et al; Onychomycosis in Eastern India - study in a peripheral tertiary care centre. Journal of Pakistan Association of Dermatologists 2013; 23 (1):14-19.

14. Agrawal A, Shanker U et al; Clinical and microbiological study of Tinea unguium in a tertiary care centre. Int. J. Curr. Microbiol. App. Sci (2015) 4(4):899-905.

15. Ahmad M, Gupta S and Gupte S. A Clinico-mycological study of onychomycosis. Egyptian Dermatol Online J, 2010; 6(4).

16. Shenoy M.M, Teerthanath.S, Karnaker V K, et al; Comparison of potassium hydroxide mount and mycological culture with histopathologic examination using periodic acid -Schiff staining of nail clipping in the diagnosis of onychomycosis. Indian J Dermatol Venereol Leprol May-June 2008, Vol 74 Issue 3, 226-29

17. Angelo T, Borgheti-Cardoso L N, Gelfuso G M et al; Chemical and physical strategies in onychomycosis topical treatment: A review. Medical Mycology 2017; 55: $461-475$.

18. Ahmad R, Kharal SA, Durani MA et al; Comparison of different laboratory methods in the diagnosis of onychomycosis. Ann Abbasi Shaheed Hosp, Karachi. 2010:15(2):127-32.

19. Gianni C, Morelli V, Cerri A, et al. Usefulness of histological examination for the diagnosis of onychomycosis. Dermatology. 2001; 202(4):283-8.

20. Wilsmann-Theis D, Sareika F, Bieber T, et al; New reasons for histopathological nail-clipping examination in the diagnosis of onychomycosis. J Eur Acad Dermatol Venereol. 2011; 25(2):235.

21. Subathra N and Santhose NB. Evaluation of diagnostic efficacy of two different microscopic techniques and fungal culture in onychomycosis. National Journal of Laboratory Medicine. 2017, Jul, Vol-6(3): 5-8.

22. Jung MY, Shim JH, Lee $\mathrm{JH}$, et al; Comparison of diagnostic methods for onychomycosis, and proposal of a diagnostic algorithm. Clin Exp Dermatol. $2015 \mathrm{Jul} ; 40(5): 479-84$.

23. Dass S M, Vinayaraj E. V., Pavavni K et al; Comparison of $\mathrm{KOH}$, Calcofluor white and fungal culture for diagnosing fungal onychomycosis in an Urban Teaching Hospital, Hyderabad. Indian Journal of Microbiology Research 2015; 2(3):148-153. 
24. Konda C, Surekha J K, Jahnavi I et al; Isolation and identification of dermatophytes in a Tertiary Care Hospital. Int. J. Curr. Microbiol. App.Sci, 2017; 6(12): 4088-4101.

25. Kaur R, Panda P S and Khan S. Non dermatophytic molds causing onychomycosis: $A$ rising trend in North India. Int J Community Med Public Health. 2017 Dec; 4(12):4532-4537.
26. Lin YC, Sun PL, Hsiao PF, Sun FJ, Wu YH. Methods for diagnosing onychomycosis: A comparative study of 459 cases. Dermatol Sin 2019; 37:63-6.

\begin{tabular}{|c|c|c|c|}
\hline \multicolumn{3}{|c|}{ AUTHORSHIP AND CONTRIBUTION DECLARATION } \\
\hline No. & Author(s) Full Name & \multicolumn{1}{|c|}{ Contribution to the paper } & Author(s) Signature \\
\hline 1 & M. Wajid Khurshid Sipra & $\begin{array}{l}\text { Conceive of idea, Data collection, } \\
\text { Writing of manuscript, Interpretation of } \\
\text { Results, Final review of manuscript. } \\
\text { Interpretation of Results, Final Review } \\
\text { of manuscript. } \\
\text { Interpretation of Results, Final Review } \\
\text { of manuscript. }\end{array}$ \\
\hline 2 & Khawar Saeed Jillian & Tayyaba Batool & \\
\hline
\end{tabular}

